\title{
The Relationship between Birth Time and Hair Whorl Location
}

\author{
Yen Lee*, Ya-Yuan Mao, Sin-Yi Huang, Yan-Wun Lin, Cai-Yun Dai, Jhao-Ru Lai, \\ Zong-Ciang Wun, Ya-Ting Cai, Sheng-Chiuan Huang
}

Department of Life Science, National Taitung University, Taitung, Taiwan

Email: *yenlee@nttu.edu.tw

Received 23 January 2015; accepted 7 February 2015; published 13 February 2015

Copyright (C) 2015 by authors and OALib.

This work is licensed under the Creative Commons Attribution International License (CC BY).

http://creativecommons.org/licenses/by/4.0/

(c) (i) Open Access

\section{Abstract}

Hair whorls may be located on the midline of the scalp or off-center, either on the left, or on the right. Some people may have more than one hair whorl on their heads. Do the locations of the hair whorls have any relationship with the time of birth? This study shows negative results which impact the validity of common Chinese folklore and superstition surrounding hair whorl characteristics.

\section{Keywords}

Hair Whorl Location, Birth Time, Chinese Folklore

Subject Areas: Anthropology

\section{Introduction}

Chinese legend says that the time of birth and the location of the hair whorl on a person's scalp are accordant. There are no published reports discussing this topic to date.

Hair whorls are a feature of human developmental biology [1]. It has been noted previously that among all mammals, only humans have hair whorls, and that each individual must have a hair whorl [2]. Some people have two or more whorls [3] [4].

In the research on human developmental biology, there are articles which suggest that handedness and the direction of scalp hair whorl rotation develop from a common genetic mechanism. Such a mechanism also controls functional specialization of brain hemispheres [5]-[8]. Klar [5] also mentioned that over 95\% of individuals manifest a single hair whorl, with homosexual men exhibiting highly significant hair whorl in a counter-clockwise rotation and straight men exhibiting clockwise hair whorl.

In order to test the accuracy and validity of Chinese legends stipulating accordance of the birth time and the ${ }^{*}$ Corresponding author.

How to cite this paper: Lee, Y., Mao, Y.-Y., Huang, S.-Y., Lin, Y.-W., Dai, C.-Y., Lai, J.-R., Wun, Z.-C., Cai, Y.-T. and Huang, S.-C. (2015) The Relationship between Birth Time and Hair Whorl Location. Open Access Library Journal, 2: e1318.

http://dx.doi.org/10.4236/oalib.1101318 
location of the hair whorl, the present experiment was designed. In Chinese fortune telling traditions, the birth time is divided into 12 sections called Zi, Chou, Yin, Mao, Chen, Si, Wu, Wei, Shen, You, Shu, and Hai. The Zi period is demarked from 23:00 on the previous day to 1:00 on the birthday. Chou follows from 1:00 to 3:00 and Yin continues from 3:00 to 5:00 on the birthday. This pattern continues with each successive period of time comprised of two hours intervals until Hai period in the evening from 21:00 to 23:00. According to Chinese legend if a person was born during the hours of Chen, Shu, Chou, or Wei periods, he or she should have two or more hair whorls. If a person was born during the hours of Yin, Shen, Si, or Hai periods, he or she should have only one hair whorl located on either the left or the right side from the midline of the head (face forward). If a person was born during the hours of $\mathrm{Zi}$, Wu, Mao, or You periods, he or she should have only one hair whorl located on the midline of the head (face forward) [9].

\section{Materials and Methods}

\subsection{Sample Collection}

Data was collected randomly from willing participants surveyed on location at National Taitung University (classrooms, dormitories, cafeteria) and Taitung Railway Station (all locations located in Taitung County, Taiwan). Data from 657individuals were collected. The form used to collect data is shown in Figure 1.

\subsection{Statistical Analysis}

Our hypothesis assumed that if a person were born in either Chen, Shu, Chou, or Wei periods, he or she should have two or more hair whorls. If a person were born in either Yin, Shen, Si, or Hai periods, he or she should have only one hair whorl and it would be located on either the left or right side from the midline of the head (face forward). If a person were born in either $\mathrm{Zi}$, Wu, Mao, or You periods, he or she should have only one hair whorl and it would be located on the midline of the head (face forward).

Samples were separated into three categories (Zi, Wu, Mao, You/Chen, Shu, Chou, Wei/and Yin, Shen, Si, Hai) and the sums of those samples which corresponded to our assumption for each category served as the observed values, while the sums of each category were used for the expected values for the calculation. For those people

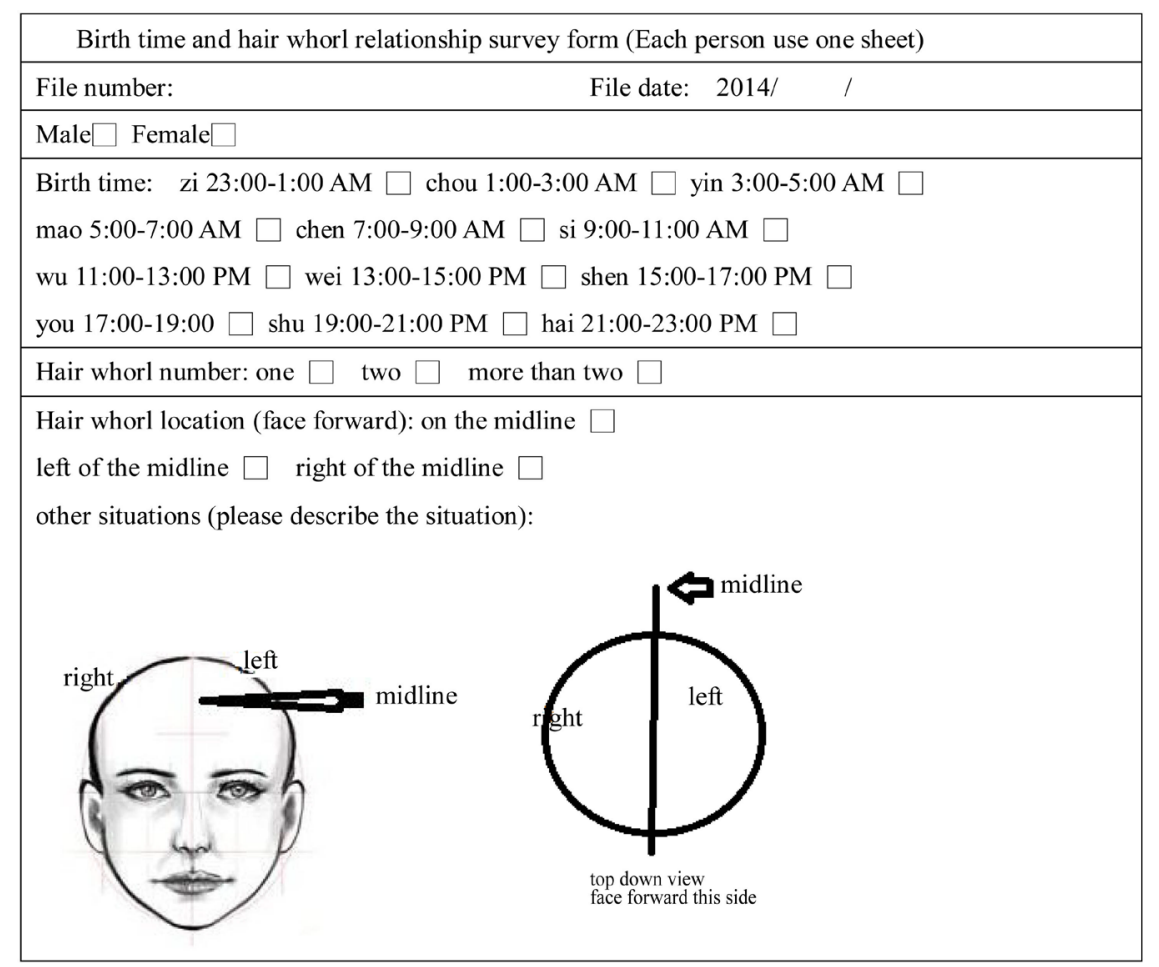

Figure 1. The form used to collect hair whorl pattern data. 
having two hair whorls, only count the number of persons, whorl locations were not count.

The Chi-test function of Microsoft Excel was used to calculate the $p$ value of $\chi^{2}$ test to confirm or disconfirm the correspondence of the observed data to the hypothesized distribution. The $95 \%$ confidence interval was chosen.

\section{Results}

A total of 291 female and 366 male samples were collected. Among those samples, the majority had one hair whorl, while 18 females had two hair whorls (6.2\%), and 27 males had two hair whorls (7.4\%). For those people possessing only one hair whorl, more than $35 \%$ were located on the midline (female $39.9 \%$, male $35 \%$ ). The remainder females, $29.9 \%$ were located on the left side of the midline and $26.8 \%$ were located on the right side of the midline. For males, $23.5 \%$ were located on the left side of the midline and $34.2 \%$ were located on the right side of the midline. Neither male nor female, have more than two hair whorl were observed.

\section{The Results of Chi-Square Tests}

None of the $p$ values were greater than 0.05 . Therefore, null hypotheses that observed locations of hair whorls were not different from folklore predictions were rejected. The calculated $p$ values are listed in Table 1.

\section{Discussion}

Chinese traditional fortune telling is still popular. Lots of people like to visit a fortune teller to get consultant when they are facing big decisions such as job promotion, marriage, running a new business, etc. And most of the time, the fortune teller will ask their clients to give their birth year, month, date, and time. Sometimes, the client cannot recall their birth time very accurately. An old Chinese legend mentioned that the hair whorl location is accordant to one's birth time. This popular legend is spread extensively among the fortune teller communities in China. And when clients cannot recall their birth time very accurately, the future teller usually will check their hair whorl location and guess the time of birth, which is important baseline "data" for many other fortune telling methods. This situation happened thousand years in China, without any scientific proof. This research is also the first time to use a scientific way to check the Chinese old legend. The authors think that lots of Chinese fortune tellers' predictions are based on long-period accumulated information. It is important to check their validity or break its blind faith. This is the first time to study the relationship between the time of birth and the location of the hair whorl pattern on the scalp. The old Chinese legend about the hair whorl locations accordant to one's birth time is not supported by the data. According to this research, in practical terms, determining a person's birth time based on hair whorl location is unreliable.

It should be noted that subjects born by caesarean delivery were not excluded in this research. In this research people with two hair whorls are 45 (6.9\%). The ratio is a little higher than Kalr surveyed. And 23 of them were born in 5 (Chen), 2 (Shu), 9 (Chou), and 7 (Wei) time period (51.1\%).

Table 1. The calculated $p$ values of Chi tests.

\begin{tabular}{|c|c|c|c|}
\hline Birth time category & Observed number & Expected number & $p$ value \\
\hline $\begin{array}{l}\mathrm{Zi}, \mathrm{Wu}, \mathrm{Mao}, \mathrm{You} \\
\text { (only those with } 1 \text { whorl } \\
\text { on the center line of the } \\
\text { midline were count) }\end{array}$ & $\begin{array}{c}40 \text { (Zi), } 20 \text { (Wu), } \\
22 \text { (Mao), } 35 \text { (You) }\end{array}$ & $\begin{array}{c}68 \text { (Zi), } 75(\mathrm{Wu}) \\
63 \text { (Mao), } 63 \text { (You) }\end{array}$ & 0.039120916 \\
\hline $\begin{array}{l}\text { Chen, Shu, Chou, Wei } \\
\text { (only those with } 2 \\
\text { whorls were count) }\end{array}$ & $\begin{array}{l}5 \text { (Chen), } 2 \text { (Shu), } \\
9 \text { (Chou), } 7 \text { (Wei) }\end{array}$ & $\begin{array}{l}\text { 61(Chen), } 31 \text { (Shu), } \\
42 \text { (Chou), } 52 \text { (Wei) }\end{array}$ & 0.000000026 \\
\hline $\begin{array}{l}\text { Yin, Shen, Si, Hai } \\
\text { (only those with } 1 \text { whorl, either } \\
\text { on the left or right side from the } \\
\text { midline were count) }\end{array}$ & $\begin{array}{c}30 \text { (Yin), } 37 \text { (Shen), } \\
29 \text { (Si), } 40 \text { (Hai) }\end{array}$ & $\begin{array}{l}46 \text { (Yin), } 54 \text { (Shen), } \\
53 \text { (Si), } 49 \text { (Hai) }\end{array}$ & 0.002665066 \\
\hline
\end{tabular}




\section{Author's Contributions}

Yen Lee: the whole experimental design, survey form design, statistical analysis, article writing, samples collection.

All the other authors: samples collection, partially participated in statistical analysis.

\section{References}

[1] Ziering, C. and Krenitsky, G. (2003) The Ziering Whorl Classification of Scalp Hair. Dermatologic Surgery, 29, 817821.

[2] Wunderlich, R.C. and Heerema, N.A. (1975) Hair Crown Patterns of Human Newborns. Clinical Pediatrics, 14, 10451049. http://dx.doi.org/10.1177/000992287501401111

[3] Lauterbach, C.E. and Knight, J.B. (1927) Variation in Whorl of the Head Hair. Journal of Heredity, 18, 107-115.

[4] Ucheya, R.E. and Igweh, J.C. (2005) Hair Whorl Patterns on the Posterior Aspect of the Scalp among Nigerians. Journal of Experimental and Clinical Anatomy, 4, 21-24. http://dx.doi.org/10.4314/jeca.v4i1.30910

[5] Kalr, A.J. (2005) A 1927 Study Supports a Current Genetic Model for Inheritance of Human Scalp Hair-Whorl Orientation and Hand-Use Preference Traits. Genetics, 170, 2027-2030. http://dx.doi.org/10.1534/genetics.104.039990

[6] Klar, A.J. (2004) Excess of Counterclockwise Scalp Hair-Whorl Rotation in Homosexual Men. Journal of Genetics, 83, 251-255. http://dx.doi.org/10.1007/BF02717894

[7] Klar, A.J. (2003) Human Handedness and Scalp Hair-Whorl Direction Develop from a Common Genetic Mechanism. Genetics, 165, 269-276.

[8] McDonald, J.H. (2011) Myths of Human Genetic. Sparky House Publishing, Baltimore, 40-45.

[9] 88say Tecnology Ltd. (2002) http://88say.fate.yam.com/DesktopModules/inc/judgment.htm (In Chinese) 
Scientific Research Publishing (SCIRP) is one of the largest Open Access journal publishers. It is currently publishing more than 200 open access, online, peer-reviewed journals covering a wide range of academic disciplines. SCIRP serves the worldwide academic communities and contributes to the progress and application of science with its publication.

Other selected journals from SCIRP are listed as below. Submit your manuscript to us via either submit@scirp.org or Online Submission Portal.
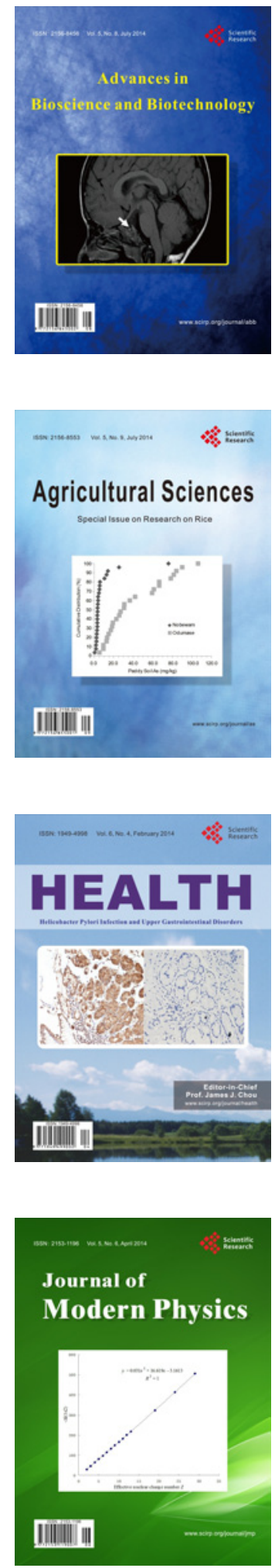
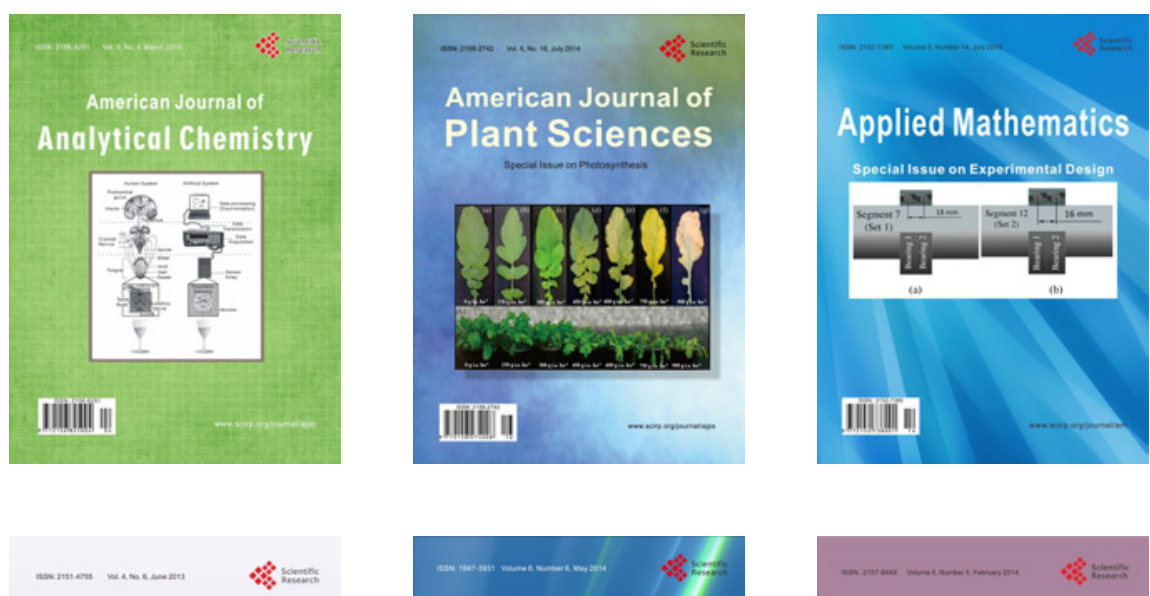

Creative Education
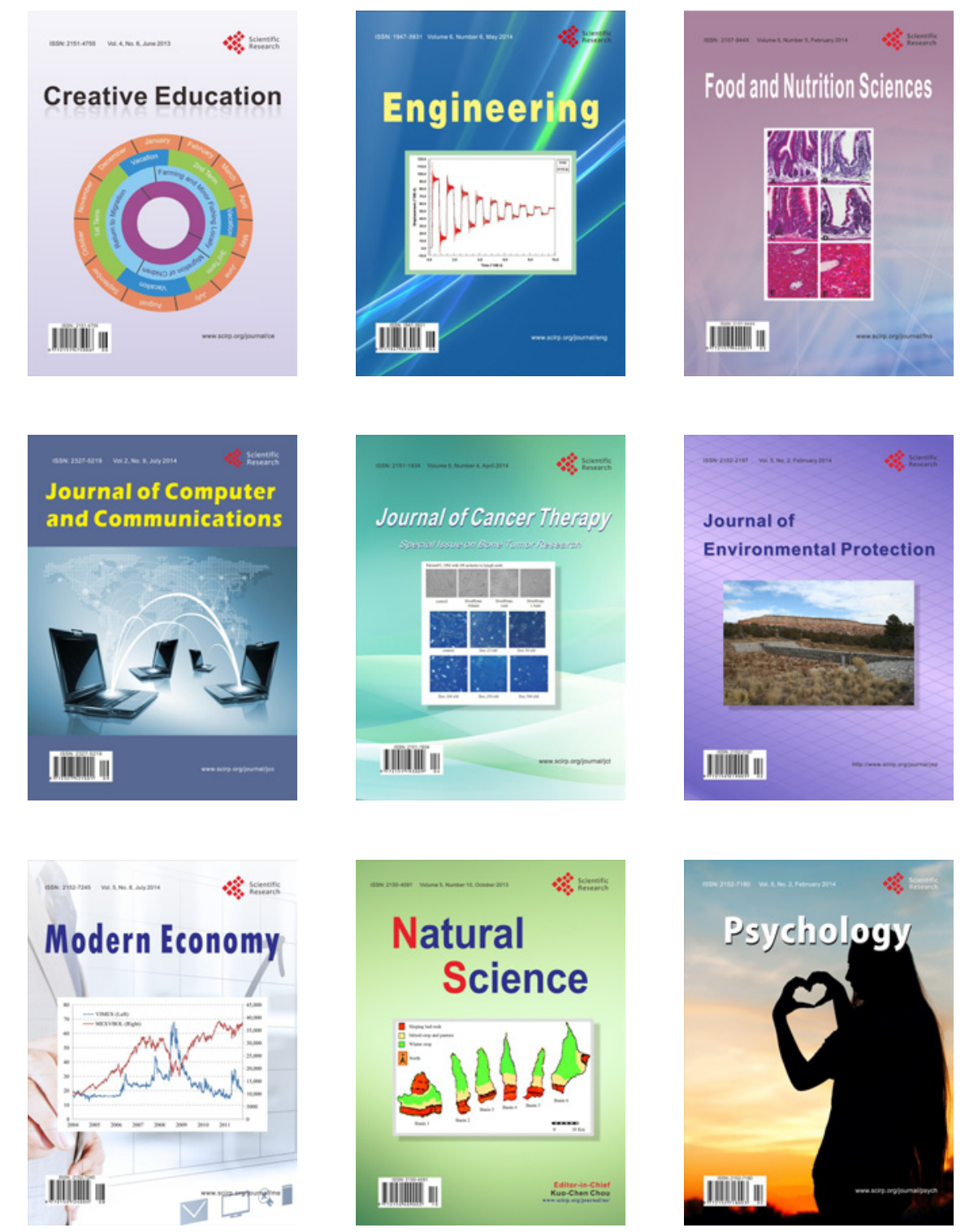